\title{
25 Research Soure \\ Cloning, Subcellular Location and Expression Analysis of Grape MYB Gene
}

\section{Guirong Li ( $D$ liguirong10@163.com )}

School of Horticulture and Landscape Architecture, Henan Institute of Science and Technology

\section{Ran Quan}

School of Horticulture and Landscape Architecture, Henan Institute of Science and Technology

\section{Pengwei Jing}

School of Horticulture and Landscape Architecture, Henan Institute of Science and Technology

\section{Meng Wang}

School of Horticulture and Landscape Architecture, Henan Institute of Science and Technology

\section{Wenwen Xu}

School of Horticulture and Landscape Architecture, Henan Institute of Science and Technology Huiling Hu

School of Horticulture and Landscape Architecture, Henan Institute of Science and Technology

\section{Research Article}

Keywords: Grape, MYB gene, Peel color, Resistance to stress, Hormone induction, gene expression

Posted Date: March 9th, 2021

DOl: https://doi.org/10.21203/rs.3.rs-258098/v1

License: (c) (i) This work is licensed under a Creative Commons Attribution 4.0 International License. Read Full License 


\section{Abstract}

$M Y B$ gene plays an important role in plant growth, development and response to abiotic stress. In this study, the Eurasian grape (Vitis vinifera L.) cultivar 'Yatomi Rosa' was used as the test material. Two MYB genes, $V V M Y B B 1$ gene and $V V M Y B A 3$ gene, were obtained by homologous cloning, and their subcellular location, different organs, and expression patterns under stress treatment and hormone induction were obtained. It was found that $V_{V M Y B B} 1$ gene and $V_{V M Y} M A 3$ gene proteins were located in the nucleus and belonged to nuclear proteins. $V V M Y B B 1$ gene and $V V M Y B A 3$ gene were highly expressed in roots and flowers. $V V M Y B B 1$ gene and $V V M Y B A 3$ gene might have a negative effect on the formation of peel color. $V V M Y B 1$ gene and $V V M Y B A 3$ gene might play an important role in drought resistance and salt stress resistance in grapes. Under the induction of exogenous hormones, the expression of $V V M Y B B 1$ gene was higher than that of $V_{V} M Y B A 3$ gene under the treatment of IAA, ETH, SA and MeJA. Expression of $V V M Y B B 1$ gene was lower than that of $V V M Y B A 3$ gene under the treatment of 6-BA, GA3 and ABA. It showed that $M Y B$ gene played an important role in the development of different organs of grapes, fruit coloring and response to abiotic stress. This would provide reference for the utilization of grape $M Y B$ gene resources.

\section{Introduction}

MYB gene is most researched in the field of plants, and it is widely involved in various processes of plant growth and development ${ }^{1,2}$. Arce-Johnson $\&$ Tornielli ${ }^{3}$ found that the phenylpropanoid pathway was controlled at different branches by a set of R2R3-MYBC2 repressors in grapevine. Li et al. ${ }^{4}$ found that three R2R3 MYB gene transcription factor genes from Capsicum annuum showing differential expression during fruit ripening. Azuma et al. ${ }^{5}$ found the genomic and genetic analysis of MYB-related genes that regulated anthocyanin biosynthesis in grape berry skin. Studies have shown that plant $M Y B$ genes exhibited specific temporal and spatial expression characteristics in different organs and tissues ${ }^{6}$.

When plants encounter abiotic stress or hormone induction, the $M Y B$ gene will also be expressed accordingly, which will initiate a series of physiological and biochemical reactions, and ultimately reduce or eliminate the damage to plants from adversity ${ }^{6}$. Studies have shown that most MYB genes are involved in the process of response to abiotic stress and hormone signals ${ }^{7}$. The qRT-PCR results of Chai et al. ${ }^{8}$ showed that the expression level of the $17 G 121000$ and GLYMA genes in soybeans would change under drought, dehydration, salt and abscisic acid (ABA) stress. Oh et al. ${ }^{9}$ found that AtMYB60 could adapt to arid environment by regulating the opening and closing of stomata and root growth. Seo et al. ${ }^{10}$ found that $A t M Y B$ enhanced the ability of Arabidopsis to resist drought stress by integrating auxin and ABA signals. Apple MdMYB88 and MdMYB124 regulated the expression of low-temperature response genes through CBF-dependent signaling pathways and enhanced the low-temperature resistance of apples $^{11}$. $35.02 \%$ and $56.85 \%$ of Arabidopsis $M Y B$ genes were up-regulated and down-regulated under salt stress, respectively ${ }^{12}$. Liao et al ${ }^{13}{ }^{1}$ identified 156 GmMYB genes in soybeans, of which 43 genes changed their expression levels under ABA, salt, drought or low temperature stress. With the deepening of 
research, more and more $M Y B$ genes have been proved to be involved in the regulation of plant abiotic stress and hormone induction ${ }^{6}$.

Grapes are one of the most important fruit trees in the world. The widely cultivated grape cultivars are mainly Eurasian grapes (Vitis Vinifera L.). These grapes have excellent quality and processing properties, but their disease resistance and stress resistance are poor ${ }^{14}$. In grapevine, 108 MYB genes have been identified from the genome of Vitis vinifera cv. Pinot Noir, which play an important role in the grape growth and development ${ }^{15}$. This study is to explore the role of the new grape $M Y B$ gene in fruit color and response to abiotic stress. Two $M Y B$ genes, $V V M Y B B 1$ gene and $V V M Y B A 3$ gene, were cloned using the RT-qPCR method, and their expression patterns under different organ development and peel color, abiotic stress and different hormone induction were analyzed to understand the effect of grape MYB gene in grape fruit coloration and response to abiotic stress. The role in the process provides a reference for the utilization of grape $M Y B$ gene resources.

\section{Results And Analysis}

\section{Gene Cloning and Sequence Analysis}

\section{Gene Cloning}

Using homologous cloning, two MYB gene fragments of $1680 \mathrm{bp}$ and $1104 \mathrm{bp}$ size were cloned using the cDNA of the leaves of the European grape 'Yatomi Rose' as the template (Fig. 1). Both contained a complete open reading frame with a sequence of $100 \%$ similarity to grape $V V M Y B B 1$ gene and $V V M Y A 3$ gene (GenBank XM_002275810 and NP_001267927, respectively). ORF total length was 1350 bp and 834 bp. $V V M Y B B 1$ gene total length was $762 \mathrm{bp}$, coding 254 amino acids, and the isoelectric point was 28.45 $\mathrm{kD}$. The total length of the $V V M Y B A 3$ gene was $477 \mathrm{bp}$, coding 159 amino acids, and the isoelectric point was 18.53 kD (Fig. 2).

VVMYBB1 (1091) 7908922-7910012 bp

$133,145,130,184,499$

VVMYBA3 (683) 12516756-12517438

$115,87,118,130,232$

Neighbor-joining method in Mega 7.0 software was used to construct the phylogenetic tree between two grape MYB sequences and 16 other plant MYB proteins (Fig. 3). After cluster analysis, it was found that two large subclasses were clustered, The first category included dates (XP_015876153), oranges, woody cotton, apples (XP_008346342), lotus, Populus euphratica, castor, cocoa (XP_007010686), VvMYBB1 gene. The second category included legumes, eucalyptus grandis, hybrids, soybeans, wild soybeans, apples (AAZ20438), cocoa (XP_007051069), dates (XP_015891841), VVMYBA3 gene. 
To construct two fusion expression vectors of $M Y B$ genes, id estpBI221-VyMYBB1 and pBI221-VyMYBA3 and confirm $V V M Y B$ subcellular localization of two proteins, pBI221-VVMYBB1-GFP and pBI221-

$V V M Y B A 3 G F P$ plasmids were transformed into Arabidopsis protoplasts. The results showed that the pBI221-VVMYBB1-GFP and pBI221-VVMYBA3GFP fusion proteins were localized in the nucleus, while the control GFP proteins covered the whole cell (Fig.2) (Fig.4).

\section{Analysis of $V V M Y B$ gene expression}

\section{Expression specificity analysis in different organs}

Fig. 5 showed that the expression of $V V M Y B B 1$ gene was the highest in root, followed by tendrils, leaves and flowers, the lowest in stem. The expression of root was 50 times of that of stem. $V V M Y B A 3$ gene expression was the highest in flowers, followed by roots, tendrils and leaves, and the lowest in stems. The expression of flower was 100 times of that of stem. These results indicated that $V V M Y B B 1$ gene and $V V M Y B A 3$ gene played an important role in the development of grape roots and flower organs of 'Yatomi Rose' grape.

The contents of $V V M Y B B 1$ gene and $V V M Y B A 3$ gene were the lowest in the early stage of fruit development, and then increased gradually, and reached the highest value 8 weeks after flower development. This showed that with the prolongation of fruit development period, the two genes played an important role in fruit maturation. Compared with the relative expression of control VVUFG, the relative expression levels of $V V M Y B B 1$ gene and $V V M Y B A 3$ gene were 5 and 14 times higher than that of $V V M Y B B 1$ gene and $V V M Y B A 3$ gene at 8 weeks after flowering, respectively. It is speculated that $V V M Y B B 1$ gene and $V V M Y B A 3$ gene have a negative effect on the formation of grape epidermis color.

The expression of $V V M Y B B 1$ gene and $V V M Y B A 3$ gene under stress treatment was shown in Fig. 6 . Under drought treatment, $V V M Y B B 1$ gene expression increased gradually, reaching the highest value at $9 \mathrm{~d}$, about 12 times of $0 \mathrm{~h}$. The expression of $V V M Y B A 3$ gene increased gradually, reaching the highest value at 9 days, about 6.5 times of $0 \mathrm{~h}$. Under the treatment of low temperature $\left(4{ }^{\circ} \mathrm{C}\right)$, the expression of $V V M Y B B 1$ gene was higher than that of $V V M Y B A 3$ gene, and the expression of $V V M Y B B 1$ gene increased gradually, reaching the highest value in $72 \mathrm{~h}$, about 12 times of $0 \mathrm{~h} . V V M Y B A 3$ gene expression changes were not obvious. Under salt treatment, the expression of $V V M Y B B 1$ gene increased first and then decreased, reaching the highest value in $12 \mathrm{~h}$, about 8 times of $0 \mathrm{~h}$. The expression of $V V M Y B A 3$ gene reached the highest value at $24 \mathrm{~h}$, about 2 times of $0 \mathrm{~h}$. The expression of $V V M Y B B 1$ gene and $V V M Y B A 3$ gene was not obvious in control water treatment. These results show that $V V M Y B B 1$ gene may play a role in the response of 'Yatomi Rose' grapes to external drought, low temperature and high salt abiotic stress, $V V M Y B A 3$ gene mainly in response to external drought and high salt abiotic stress. These results suggest that $V V M Y B 1$ gene and $V V M Y B A 3$ gene may play an important role in grape drought resistance and salt stress resistance.

The expression of $V V M Y B B 1$ gene and $V V M Y B A 3$ gene under exogenous hormone treatment was shown in Fig. 7. $V_{V M Y B B 1}$ gene expression was higher than $V_{V} M Y B A 3$ gene expression under Indole-3-Acetic 
Acid (IAA), ethylene (ETH), salicylic acid (SA), methyl jasmonate (MeJA) treatment, and lower than that under 6-Benzyladenine (6-BA), Gibberellin $\mathrm{A} 3\left(\mathrm{GA}_{3}\right)$, abscisic acid ( $\mathrm{ABA}$ ) treatment. Under IAA treatment, the expression of $V V M Y B B 1$ gene increased first and then decreased. At $12 \mathrm{~h}$, the expression reached the highest, about 5 times of 0 h. $V V M Y B A 3$ gene expression showed a downward trend. Under $\mathrm{GA}_{3}$ treatment, the $V y M Y B B 1$ gene and $V Y M Y B A 3$ gene expression increased first and then decreased, and the $V y M Y B B 1$ gene expression reached the maximum value in $12 \mathrm{~h}$, about 10 times of $0 \mathrm{~h}$. The expression of $V Y M Y B A 3$ gene reached the maximum at $9 \mathrm{~h}$, about 2.2 times of $0 \mathrm{~h}$. Under the treatment of 6-BA, the expression of $V Y M Y B B 1$ gene and $V Y M Y B A 3$ gene increased first and then decreased, and the $V Y M Y B B 1$ gene expression reached the maximum at $9 \mathrm{~h}$, about 6 times of $0 \mathrm{~h}$. The expression of $V y M Y B A 3$ gene reached the maximum in $3 \mathrm{~h}$, about 1.2 times of $0 \mathrm{~h}$. Under the treatment of ETH, the VYMYBB1 gene expression increased first and then decreased, and the $V Y M Y B B 1$ gene expression reached the maximum at $48 \mathrm{~h}$, about 9 times of $0 \mathrm{~h}$. VYMYBA3 gene expression showed a downward trend. The VYMYBB1 gene expression of $A B A$ increased first and then decreased, and the $V Y M Y B B 1$ gene expression reached the maximum value in $12 \mathrm{~h}$, about 4 times of $0 \mathrm{~h}$. VYMYBA3 gene expression showed an upward trend. VYMYBA3 gene expression reached the maximum at $72 \mathrm{~h}$, about 11 times of $0 \mathrm{~h}$. Under the treatment of SA, VYMYBB1 gene expression increased first and then decreased reached the maximum at $9 \mathrm{~h}$, about 8 times of 0 h. VYMYBA3 gene expression decreased. Under MeJA treatment, VyMYBB1 gene expression increased first and then decreased. At $12 \mathrm{~h}$, the expression reached the highest, about 7.3 times of $0 \mathrm{~h}$. $V V M Y B A 3$ gene expression showed a downward trend. The expression levels of $V y M Y B B 1$ gene and $V y M Y B A 3$ gene were not obvious in control water treatment at different times. These results indicate that VYMYBB1 gene and $V Y M Y B A 3$ gene play a very important role in physiological activities regulated by exogenous hormones in 'Yatomi Rose' grape.

\section{Discussion}

Plants in response to abiotic stress such as drought, chilling injury and salt, plant defense response can itself quickly in order to survive, the induced stress response genes, antioxidants such as adversity the expression of related genes to change its metabolic processes to maintain normal stress under the condition of cells, to ensure the growth of plants ${ }^{14}$. Plant $M Y B$ genes are widely involved in response to abiotic stress, and they directly or indirectly regulate the expression of the corresponding stress response genes to further enhance the ability of resistance to abiotic stress ${ }^{6}$.

Most of the $M Y B$ genes in plants control different development processes and stress tolerance ${ }^{6}$. The cloned $V V M Y B B 1$ gene and $V V M Y B A 3$ gene encoded proteins contained two $\mathrm{R}$ domains. The transient transformation of $V V M Y B$ gene in onion epidermal cells showed that these two genes were localized in the nucleus, indicating that $V V M Y B B 1$ gene and $V V M Y B A 3$ gene proteins play a role in regulating the transcription level of other genes in the nucleus. It is consistent with the research results of Xie et al. ${ }^{16}$, Liu et al. ${ }^{17}$ and Zhu et al. ${ }^{15}$, gene are usually expressed in the nucleus and can specifically bind to cisacting elements in the promoter region of eukaryotic genes to regulate gene expression. 
Plant $M Y B$ gene shows specific spatiotemporal expression characteristics in different organs and tissues $^{6}$. In this study, the expression of $V_{V M Y B B 1}$ gene and $V_{V M Y B A 3}$ gene were specific in different tissues, with the highest expression of $V V M Y B B 1$ gene in roots and the highest expression of $V V M Y B A 3$ gene in flowers. Zhu et al. ${ }^{15}$ also found that $V V M Y B C 2 L 2$ gene was shown to be strongly expressed in root, flower and seed tissue, but Cavallini et al. ${ }^{18}$ found in grape vine 'Corvina', MYBC2L2 showed very low expression levels in almost all organs including the berry and seed. These results indicated that $M Y B$ gene expression was different in different organs of grape, suggesting that these two genes played a role in root and flower development of grape, respectively. In addition, by measuring the expression levels of $V V M Y B B 1$ gene and $V V M Y B A 3$ gene in grape peel of 'Yatomi Rose' at different stages of fruit development, compared with the relative expression levels of control VVUFG, the content of $V V M Y B B 1$ gene and $V V M Y B A 3$ gene decreased, suggesting that $V V M Y B B 1$ gene and $V V M Y B A 3$ gene had a negative effect on the formation of grape peel color of 'Yatomi Rose'. There are many MYB genes involved in the regulation of anthocyanin synthesis in grape, such as $V v M Y B A 1$ gene, $V V M Y B A 2$ gene, $V V M Y B A 6$ gene ${ }^{19-21}$. Zhu et al. ${ }^{15}$ found $V V M Y B C 2 L 2$ gene weakly expressed during the fruit development in grapevine, it suggested that $V V M Y B C 2 L 2$ gene played a role as a negative function of anthocyanin biosynthesis. Ni et al. ${ }^{22}$ studied that Ethylene-activated PpERF105 induced the expression of PpMYB140 to inhibit anthocyanin biosynthesis, and then the $P p M Y B 140$ gene played a negative function in red pear fruit. The results of these studies are consistent with the results of this study, suggesting that $V V M Y B B 1$ gene and $V V M Y B A 3$ gene have a negative effect on the formation of grape skin color of 'Yatomi Rose' grape.

The $M Y B$ gene family plays an important role in many physiological processes in plants, such as cell cycle, environmental response, and stress response. With further research, some of the MYB genes involved have been gradually discovered ${ }^{6,23} . M Y B$ gene is involved in various aspects of plant response to abiotic stress. AtMYB96 in Arabidopsis thaliana regulates drought stress responses by integrating ABA and IAA signals ${ }^{24}$. The expression of SCMYBAS1 gene affects the response of sugarcane to drought and salt stress ${ }^{25}$. Yang et al. ${ }^{26}$ showed that the expression of OsMYB2 could be induced by salt stress, cold and drought in rice. Hao et al. ${ }^{27}$ showed that MdMYB308L acted as a positive regulator in low temperature stress. In this study, $V V M Y B B 1$ gene and $V V M Y B A 3$ gene expressions were changed in 'Yatomi Rose' grape under three stress conditions (low temperature, high salt and drought). VVMYBB1 gene had the strongest response to different stress conditions. This suggests that $V V M Y B B 1$ gene may play an extremely important role in drought, low temperature and salt stress. Our results also indicate that $M Y B$ gene is involved in various aspects of response to abiotic stress in grape.

Previous studies also found that $M Y B$ gene was involved in the plant hormone response process ${ }^{6}$. For example, in Arabidopsis, multiple $M Y B$ gene were found to be involved in the response of auxin, ethylene and cytokinin, and the $A T M Y B 2$ gene in Arabidopsis was induced by $A B A$, which was the first $M Y B$ gene induced by ABA in Arabidopsis ${ }^{28}$. Chen et al. ${ }^{29}$ cloned 163 MYB genes in Arabidopsis thaliana and studied the treatment with exogenous hormones ABA, ETH, GA, IAA, JA and SA; The results showed that the expression levels of half of the MYB genes were changed when treated with $S A$, and $44 \%$ of them 
were upregulated. The expression of TAMYB4 gene in wheat was regulated by SA, ABA and MeJA ${ }^{30}$. PacMYBA expression in sweet cherry (Prunus avium) was induced by salt, MeJA and $S A^{31}$. In this study, exogenous hormones IAA, GA, 6-BA, ABA, Eth, SA and MeJA treated the material, exogenous hormones induced the expression of $V V M Y B B 1$ gene and $V V M Y B A 3$ gene changed at different times, and $V V M Y B B 1$ gene induced the expression of different exogenous hormones was higher. These results indicate that plant $M Y B$ gene is widely involved in the regulation of exogenous hormones in plant growth. Other expression patterns and interactions of the two genes need to be further studied and utilized.

\section{Conclusion}

In this study, two new MYB genes were cloned from the Eurasian cultivar 'Yatomi Rose' grape. Fluorescence microscopy showed that $V V M Y B B 1$ gene and $V V M Y B A 3$ gene proteins were located in the nucleus and belonged to nuclear proteins. The expression levels of $V V M Y B B 1$ gene and $V V M Y B A 3$ gene were high in both roots and flowers, which promoted fruit ripening and had a negative effect on pericarp coloring. $V V M Y B 1$ gene and $V V M Y B A 3$ gene may play an important role in grape drought resistance and salt stress under stress conditions. Under the induction of exogenous hormones, the expression of was higher than that of $V V M Y B A 3$ gene under the treatment of IAA, ETH, SA and MeJA, while the expression of $V V M Y B B 1$ gene under the treatment of 6-BA, GA3 and ABA was lower than that of $V v M Y B A 3$ gene. These results indicate that $V V M Y B B 1$ gene and $V V M Y B A 3$ gene play an important role in the development of different organs, fruit coloration and response to abiotic stress in grape. This study provides reference for the utilization of $M Y B$ gene resources in grape.

\section{Materials And Methods}

\section{Test materials and their treatment}

The experimental material was 4-year-old European grape (Vitis Vinifera L.) 'Yatomi Rose', which was stored in the Grape Germplasm Resource Nursery of Henan Institute of Science and Technology. New roots, tendrils, shoots and stems, mature leaves and flowers with caps are collected in May. The skins came from grapes at 2, 3, 5, 7 and 8 weeks after flowering. Hormones and stress treatment materials were obtained from 1-year-old cuttings, which were stored in a greenhouse. Plastic pot size was $25 \mathrm{~cm}$ high and diameter was $30 \mathrm{~cm}$. The cultivation substrate was garden soil: peat soil $=1: 1$, placed in the plant incubator or incubator at $25-28{ }^{\circ} \mathrm{C}$, light intensity $3000 \mathrm{~lx}$, light duration $14 \mathrm{~h}$ light /10 $\mathrm{h}$ darkness.

Abiotic stress treatment: The control group was sprayed with sterile water, covered with white plastic bags, and the leaves were harvested at 0, 1, 2, 3, 4, 5, 7 and 9 days after treatment; Dryness treatment started when the water content of basin soil was $70 \%$, and leaves were harvested $0,1,2,3,4,5,7$ and 9 days after treatment; Under low temperature treatment, potted seedlings were placed in $4{ }^{\circ} \mathrm{C}$ light incubator, and the leaves were harvested at $0,3,6,9,12,24,48$ and $72 \mathrm{~h}$ after treatment; High-salt treatment, with $0.1 \mathrm{~mol} / \mathrm{L} \mathrm{NaCl}$ irrigation once, until the basin bottom solution outflow, leaves were harvested at $0,3,6,9,12,24,48$ and $72 \mathrm{~h}$ after treatment. 
Hormone treatment: Four to six leaves of lower tip were uniformly sprayed with 7 kinds of hormones in a spray can. The control group was sprayed with sterile water and covered with a white plastic bag. The leaves were harvested at $0,3,6,9,12,24,48$ and $72 \mathrm{~h}$ after treatment. The growth regulator concentration is: $500 \mathrm{mmol} / \mathrm{L} \mathrm{IAA}$ (purity >=99\%), $120 \mu \mathrm{mol} / \mathrm{L} \mathrm{GA}$ (purity >=95\%), $100 \mu \mathrm{mol} / \mathrm{L} \mathrm{6-BA} \mathrm{(purity} \mathrm{>=99 \% ),}$ $3 \mathrm{mmol} / \mathrm{L}$ Eth (purity >=85\%), $100 \mu \mathrm{mol} / \mathrm{L}$ ABA (purity >=99\%), $100 \mu \mathrm{mol} / \mathrm{L} \mathrm{SA}$ (purity >=99\%), $50 \mu \mathrm{mol} / \mathrm{L}$ MeJA (purity $>=95 \%$ ) solution.

All the treated materials were immediately frozen in liquid nitrogen and stored in $-80{ }^{\circ} \mathrm{C}$ refrigerator. All the above experiments selected 'Yatomi Rose' grape plants with the same growth potential. Each treatment was repeated for 3 times, and each pot was used as a replicate.

\section{Methods}

\section{RNA extraction and reverse transcription}

RNA extraction kit (OMEGA) was used to extract total RNA from European grape leaves, with DNase $\otimes$ to purify DNA for $1 \%$ agarose gel electrophoresis and concentration measurement, to ensure the integrity of RNA pollution-free (OD260/280 > 1.8, OD260/280 > 2.0). The first strand of cDNA was synthesized by MMLV reverse transcriptase (PrimeScriptTM $\otimes 1$ st Strand cDNA Synthesis Kit) (TaKaRa, Dalian, China).

\section{Cloning of full-length $V V M Y B$ gene}

According to the European Grape Pinot Gris Genomic Database, Primer 5.0 was used to design the primers:

VVMYBB1-F®5' ggccatggcggattcgggtaaagattc

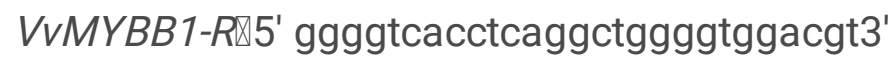

VVMYA3-F®5' gggccatggaaaataaggggaatgtgctg3'

VVMYA3-R®5' ggggtcacctcaagaagaatgaacctgcag3'

Using cDNA from the leaves of the European grape 'Yatomi Rose' as a template, primerstar GXL DNA Polymerase (TAKARA) was used for PCR amplification. The reaction procedure was denatured at $95{ }^{\circ} \mathrm{C}$ for $2 \mathrm{~min} ; 94^{\circ} \mathrm{C}$ denaturation for $30 \mathrm{~s}, 60^{\circ} \mathrm{C}$ annealing for $30 \mathrm{~s}$, extension for $2 \mathrm{~min}, 30$ cycles; the total extension was $10 \mathrm{~min}$ at $72{ }^{\circ} \mathrm{C}$. PCR products were recovered and sent to Shanghai Sangon Biotechnology Co., Ltd for sequencing.

\section{Subcellular localization}

The sequence 3 'and 5 ' of $V V M Y B B 1$ gene and $V V M Y B A 3$ gene amplified by PCR contained XBAI and $\mathrm{KPNI}$ restriction sites and did not contain the open reading frame sequences of the stop codon. After 
digestion, it was inserted into the expression vector pBI221-GFP to construct $\mathrm{pBI} 221-V v M Y B 1-\mathrm{GFP}$ and pBI221-VvMYBA3-GFP.

The inner epidermis of onion scales were exfoliated and placed on hypertonic solid MS medium for $4 \mathrm{~h}$ at $28{ }^{\circ} \mathrm{C}$. Preparation of gene gun microprojectile: Weighed 0.4-0.8 mg gold powder, disinfected with $70 \%$ ethanol, and washed with sterile water; Add 50\% glycerin and set aside. Add 3-5 g plasmid carrying target gene into $6 \mathrm{~L}$ gold powder suspension and mix; At the same time, $4 \mathrm{~L}$ of spermidine $0.1 \mathrm{M}$ and $6 \mathrm{~L}$ of $2.5 \mathrm{M}$ $\mathrm{CaCl}_{2}$ were added to vortex for $2-3 \mathrm{~min}$. Ice bath for $15 \mathrm{~min}$. Centrifuged at $12000 \mathrm{rpm}$ for 10 s, supernatant was discarded, and $20 \mathrm{~L}$ anhydrous ethanol was added for resuspended precipitation; $20 \mu \mathrm{L}$ microprojectiles were taken with pipetting gun and evenly and rapidly coated on the bearing film. Ethanol was allowed to evaporate under natural conditions. Refer to the PSD-1000 manual for the transformation of gene gun. Fluorescence microscopy (LSM510; Carl Zeiss Thornwood, NY, USA) were observed and images were collected. The green fluorescence excitation wavelength was $488 \mathrm{~nm}$.

\section{Real-time quantitative PCR}

Primers designed using Primer 5.0:

VvMYB1-F冈gagaagaagaggataccatcattg3'

VVMYB1-R囚5' ctttttcaggtgtgtgtgccagac3'

VVMYA3-F®5' cagatggtccttgattgcgggtag3'

VvMYA3-R囚5' tggttttagaatgtgtttggggtt3'

VvUFGT-R囚5' gatatggcagcagagatgggg3'

VvUFGT-Fヌ5' tgcgtgagaagagcgagttta3'

VvActin- $F \otimes 5^{\prime}$ ctggattctggtgatggtgtgagt 3'

VvActin- $R \llbracket 5^{\prime}$ cagcaaggtcaagacgaaggatag3'

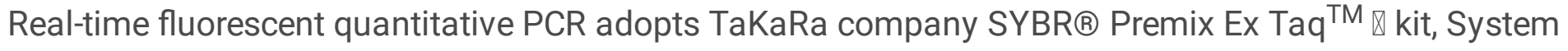
as follows: SYBR Premix Ex Taq $\mathbb{1 0} \mu \mathrm{L}$, the upstream and downstream primers were $0.8 \mu \mathrm{L}$ each, and the cDNA template was $150 \mathrm{ng}$. Finally, the cDNA template was supplemented with double steamed water to $20 \mu \mathrm{L}$, and each treatment had three biological replicates. A two-step method was performed on a CFX96 fluorescent quantitative PCR instrument (BioRad). The procedure was denatured at $95^{\circ} \mathrm{C}$ for $30 \mathrm{~s}$. There were 40 cycles of denaturation at $95^{\circ} \mathrm{C}$ for $10 \mathrm{~s}$ and annealing extension at $60^{\circ} \mathrm{C}$ for $30 \mathrm{~s}$. The Actin gene of grape was used as internal reference. The relative expression level was calculated by $2^{\square}$ $\Delta \Delta \mathrm{ct}$ method. The fluorescence values at each time point were repeated by three techniques, and the average value was taken to make the graph. 


\section{Declarations}

\section{Author contributions}

Guirong Li, Ran Quan and Huiling Hu conceived and designed the experiments. Guirong Li, Ran Quan, Huiling Hu, Wenwen Xu, Pengwei Jing, Meng Wang conducted the experiments, participated in the data analysis, data interpretations and investigation. Guirong Li wrote the manuscript and revised the original manuscript. All authors have read and approved the final manuscript.

\section{Competing interests}

Te authors declare no competing interests.

\section{Statement}

The trial was conducted in full compliance with the IUCN Policy Statement on Research Involving Species at Risk of Extinction and the Convention on the Trade in Endangered Species of Wild Fauna and Flora.

\section{References}

1. Schmitz, G., Tillmann, E. \& Carriero, F. The tomato Blind gene encodes a MYB transcription factor that controls the formation of lateral meristems. PNAS. 99(2), 1064-1069 (2002).

2. Qi, Y. T. et al. Identification of the Eutrema salsugineum EsMYB90 gene important for anthocyanin biosynthesis. BMC Plant Biol. 20(12), 176-185 (2020).

3. Arce-Johnson, P.\& Tornielli, G. B. The phenylpropanoid pathway is controlled at different branches by a set of R2R3-MYB C2 repressors in grapevine. Plant Physiol. 167(4), 1448-1470. (2015).

4. Li, J. G., Li, H. L.\& Peng, S. Q. Three R2R3 MYB transcription factor genes from capsicum annuum showing differential expression during fruit ripening. Afirican J. of Biotechnol. 10(42), 8267-8274 (2011).

5. Azuma, A. et al. Genomic and genetic analysis of Myb-related genes that regulate anthocyanin biosynthesis in grape berry skin. Theoretical Appl. Genetics. 117(6), 1009-1019. https://doi.org/10.1007/s00122-008-0840-1 (2008).

6. Jiang, C. K.\& Rao, G.Y. (2020). Insights into the diversification and evolution of R2R3-MYB transcription factors in plants. Plant Physiol. 183(2), 637-655. https://doi.org/10.1104/pp.19.01082 (2020).

7. Denekamp, M.\& Smeekens, S. C. Integration of wounding and osmotic stress signals determines the expression of the AtMYB102 transcription factor gene. Plant Physiol. 132(3), 1415-1423 (2003).

8. Chai, C.et al. Soybean transcription factor ORFeome associated with drought resistance: a valuable resource to accelerate research on abiotic stress resistance. BMC Genomics. 16(1), 596 (2015).

9. Oh, J. E. et al. A dual role for MYB60 in stomata regulation and root growth of Arabidopsis thaliana under drought stress. Plant Mol. Biol. 77(1-2), 91-103 (2011). 
10. Seo, P. J. et al. The MYB96 transcription factor mediates abscisic acid signaling during drought stress response in Arabidopsis. Plant Physiol. 151(1), 275-289 (2009).

11. Xie, Y. P. et al. An atypical R2R3MYB transcription factor increases cold hardiness by CBF-dependent and CBF-independent pathways in apple. New phytologist. 218(1), 201-218 (2018).

12. Katiyar, A. et al. Genome-wide classify action and expression analysis of $M Y B$ transcription factor families in rice and Arabidopsis. BMC Genomics. 13, 544 (2012).

13. Liao, Y. et al. Soybean GmMYB76, GmMYB92, and GmMYB177genes confer stress tolerance in transgenic Arabidopsis plants. Cell. Res. 18(10), 1047-1060 (2008).

14. Yu, Y. H. et al. Vitis vinifera bZIP14 functions as a transcriptional activator and enhances drought stress resistance via suppression of reactive oxygen species. J. Berry Res. 10(4), 1-12. https://doi.org/10.3233/JBR-200523 (2020).

15. Zhu, Z. G. et al. A R2R3-MYB Transcription Factor, $V V M Y B C 2 L 2$, Functions as a transcriptional repressor of Anthocyanin biosynthesis in grapevine (Vitis vinifera). Molecules. 24(1), 92-1-92-13. https://doi.org/10.3390/molecules24010092 (2019).

16. Xie, R. J. et al. Genome-wide analysis of citrus $R 2 R 3 M Y B$ genes and their spatiotemporal expression under stresses and hormone treatments. PLoS One. 9(12), e113971 (2014).

17. Liu, Y. F. et al. 2017. Expression differences of pigment structural genes and transcription factors explain flesh coloration in three contrasting Kiwifruit cultivars. Frontiers in Plant Sci. 8, 1507. https://doi.org/10.3389/fpls.2017.01507 (2017).

18. Cavallini, E. et al. The phenylpropanoid pathway is controlled at different branches by a set of R2R3MYB C2 repressors in grapevine. Plant Physiol. 167(4), 1448-470 (2015).

19. Cutanda-perez, M. C. et al. Ectopic expression of VImybA1 in grapevine activates a narrow set of genes involved in anthocyanin synthesis and transport. Plant Mol. Biol. 69(6), 633-648. https://doi.org/10.1007/s11103-008-9446-x (2009).

20. Kobayashi, S., Goto-yamamotog, N.\& Hirochika, H., 2004. Retrotransposon-induced mutations in grape skin color. Sci. 304(5673), 982. https://doi.org/10.1126/science.1095011 (2004).

21. Sun, L. et al. Transcriptome analysis of genes involved in anthocyanins biosynthesis and transport in berries of black and white spine grapes (Vitis davidii). Hereditas. 17(1), 153. https://doi.org/10.1186/s41065-016-0021-1 (2016).

22. Ni, J. B., et al. Ethylene-activated PpERF105 induces the expression of the repressor-type R2R3-MYB gene PpMYB140 to inhibit anthocyanin biosynthesis in red pear fruit. The Plant J. 105(1) (2020).

23. Xu, Q., He, J., Dong, J. H., Hou, X. J.\& Zhang, X. 2018. Genomic survey and expression profiling of the MYB gene family in watermelon. Horticultural Plant J. 4 (1), 1-15 (2018).

24. Seo, P. J.\& Park, C. M. MYB96-mediated abscisic acid signals induce pathogen resistance response by promoting salicylic acid biosynthesis in Arabidopsis. New Phytologist. 186(2), 471-483 (2010).

25. Prabu \& \& Prasad囚 D. T. Functional characterization of sugarcane $M Y B$ transcription factor gene promoter (PSCMYBASI) in response to abiotic stresses and hormones. Plant Cell Reports.4, 661-669 
(2012).

26. Yang, A., Dai, X. Y.\& Zhang, W. H. A R2R3-type MYB gene, OsMYB2, is involved in salt, cold, and dehydration tolerance in rice. J. of Experimental Botany. 63(7), 2541-2556 (2012).

27. Hao,Y. J.et al. An apple MYB transcription factor regulates cold tolerance and anthocyanin accumulation and undergoes MIEL1-mediated degradation. Plant Biotechnol. J. 18(2), 337353(2020).

28. Abe, H. et al. Role of arabidopsis $M Y C$ and $M Y B$ ehomologs in drought and abscisic acid-regulated gene expression. Plant Cell. 9, 1859-1868 (1997).

29. Chen, Y. H. et al. The MYB transcription factor superfamily of arabidopsis: expression analysis and phylogenetic comparison with the rice MYB Plant Mol. Biol. 60(1), 107-24. https://doi.org/10.1007/s11103-005-2910-y (2006).

30. Nashaat, A. M., Wang, X. J., Abou-attia, M. A.,Duan, X. Y.\& Kang, Z. S. A novel TaMYB4 transcription factor involved in the defense response against Puccinia striiformis $f$. sp. tritici and abiotic stresses. Plant Mol. Biol. 84(5), 589-603 (2014).

31. Shen, X. J. et al. PacMYBA, a sweet cherry R2R3-MYB transcription factor, is a positive regulator of salt stress tolerance and pathogen resistance. Plant Physiol. and Biochemistry. 112, 302-311 (2017).

\section{Figures}
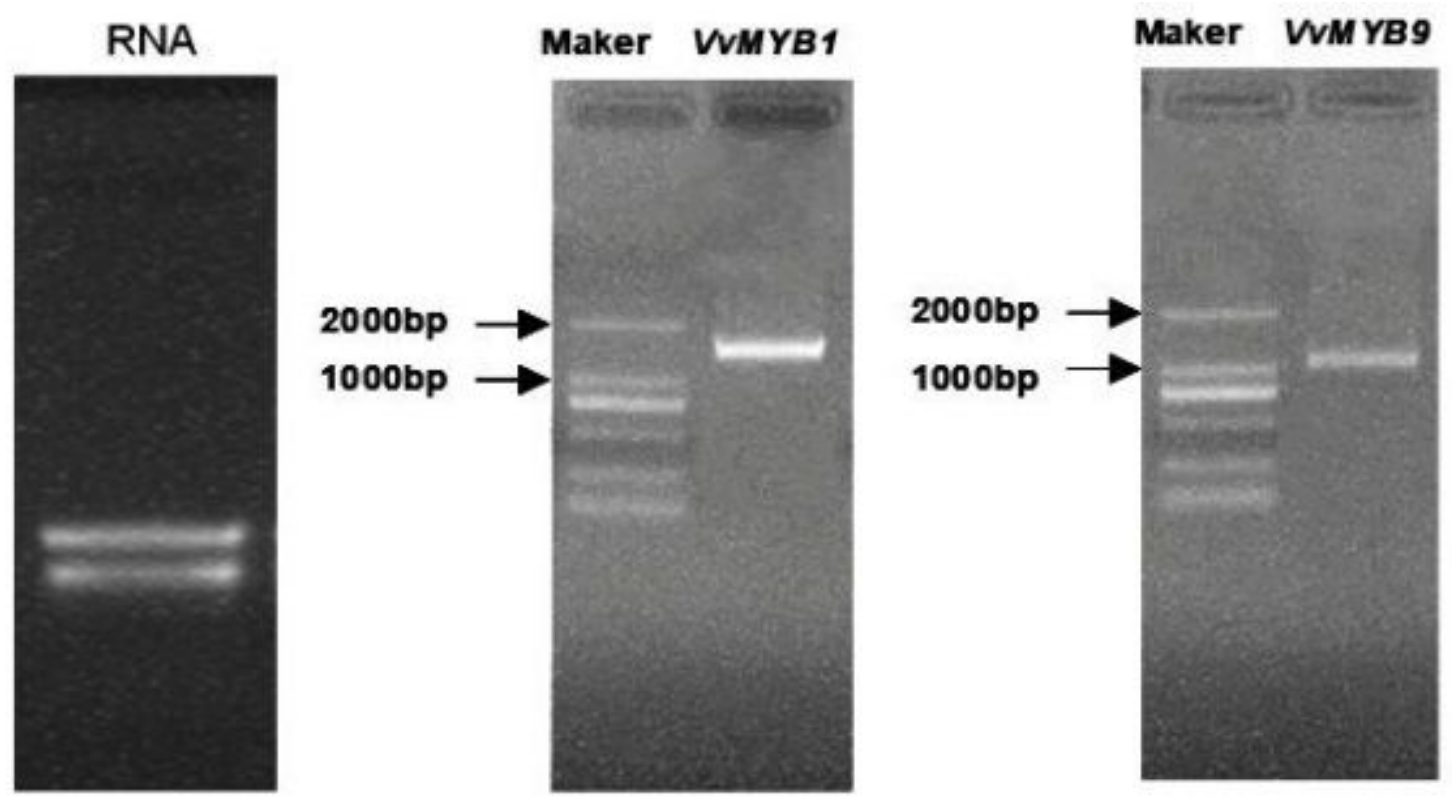

\section{Figure 1}

Cloning of VvMYB two genes in grapevine. 


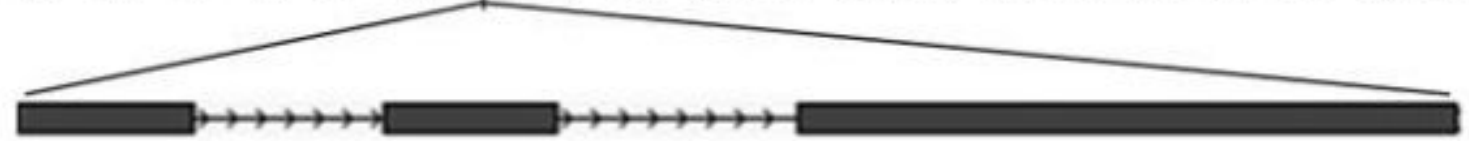

IVMYBBI

Overvieu of chr2

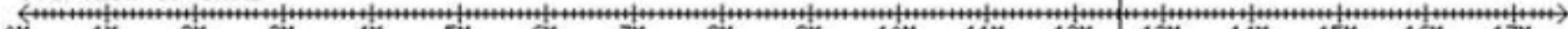
or 19

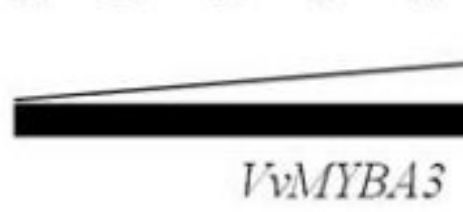

Figure 2

Sequence analysis of two genes MYB grape.

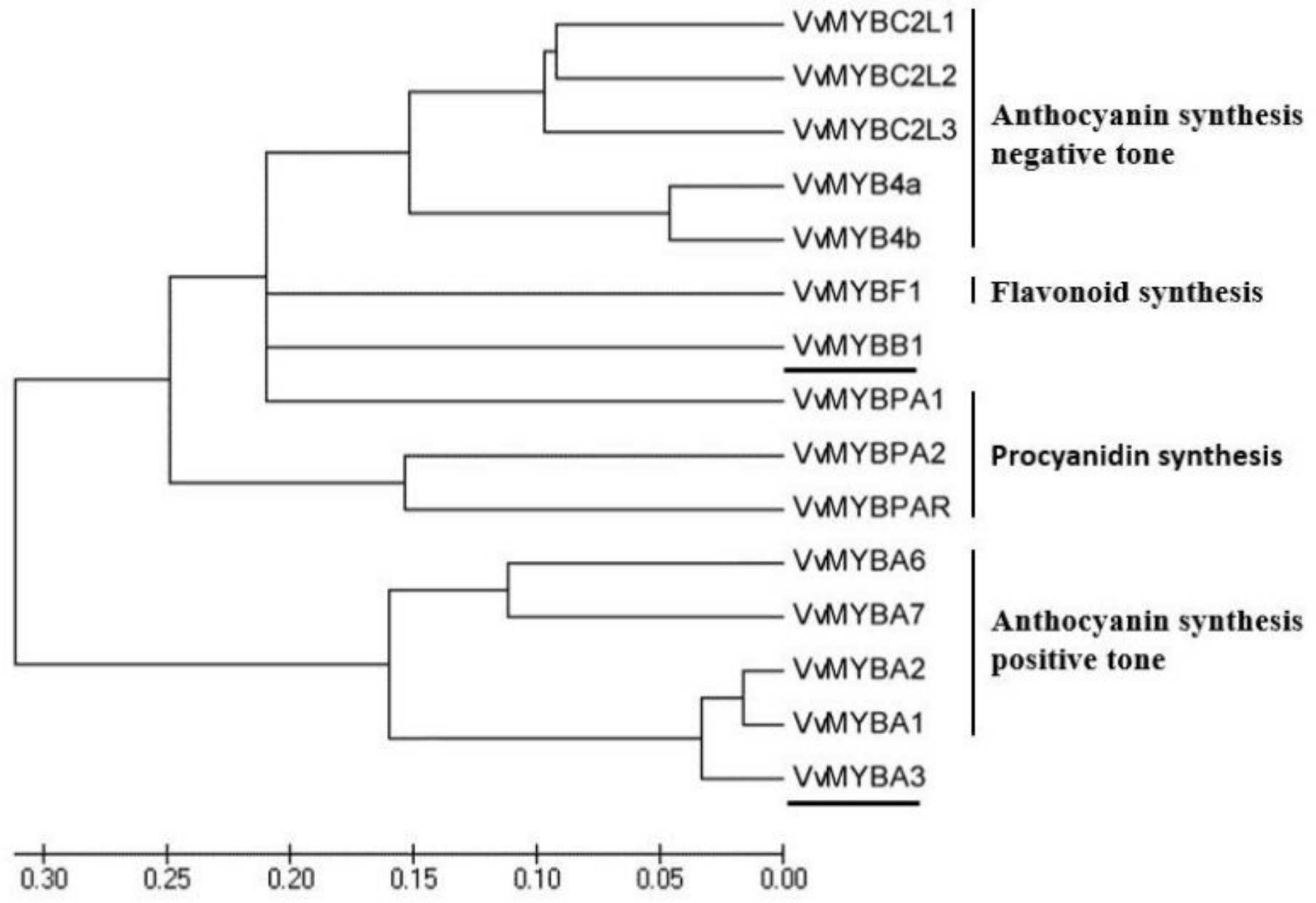

Figure 3

Phylogenetic tree of VvMYBB1 gene and VvMYBA3 gene of the grapevine with other species MYB proteins. 


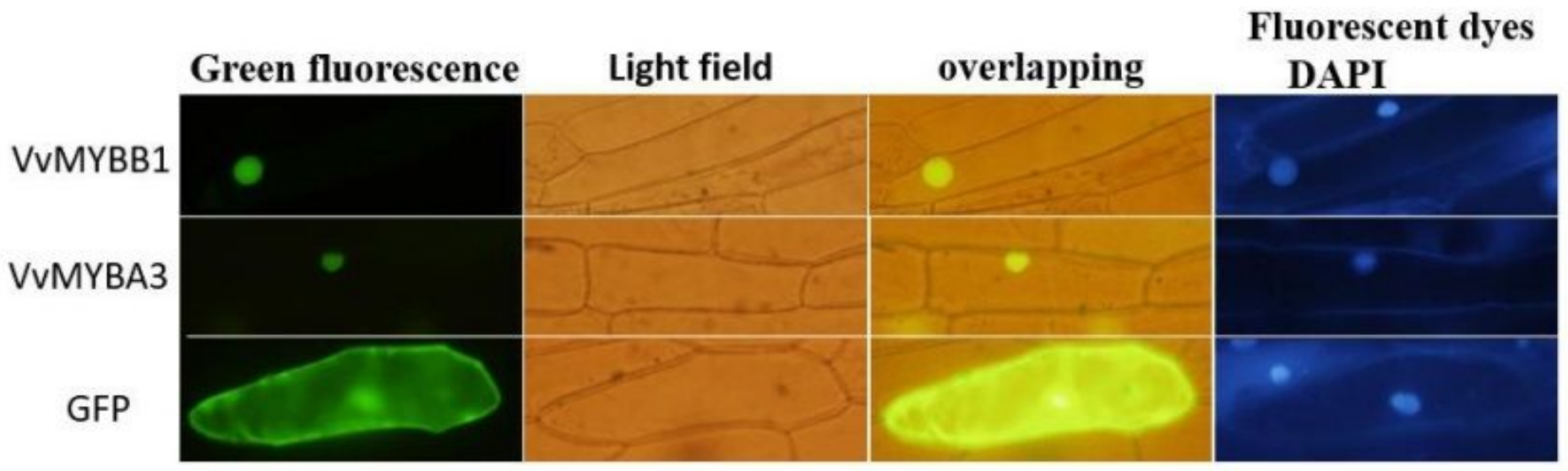

Figure 4

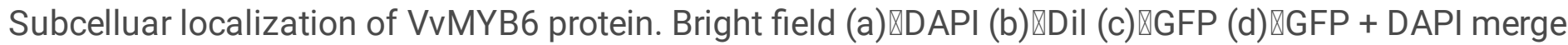

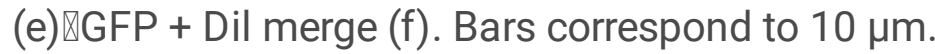
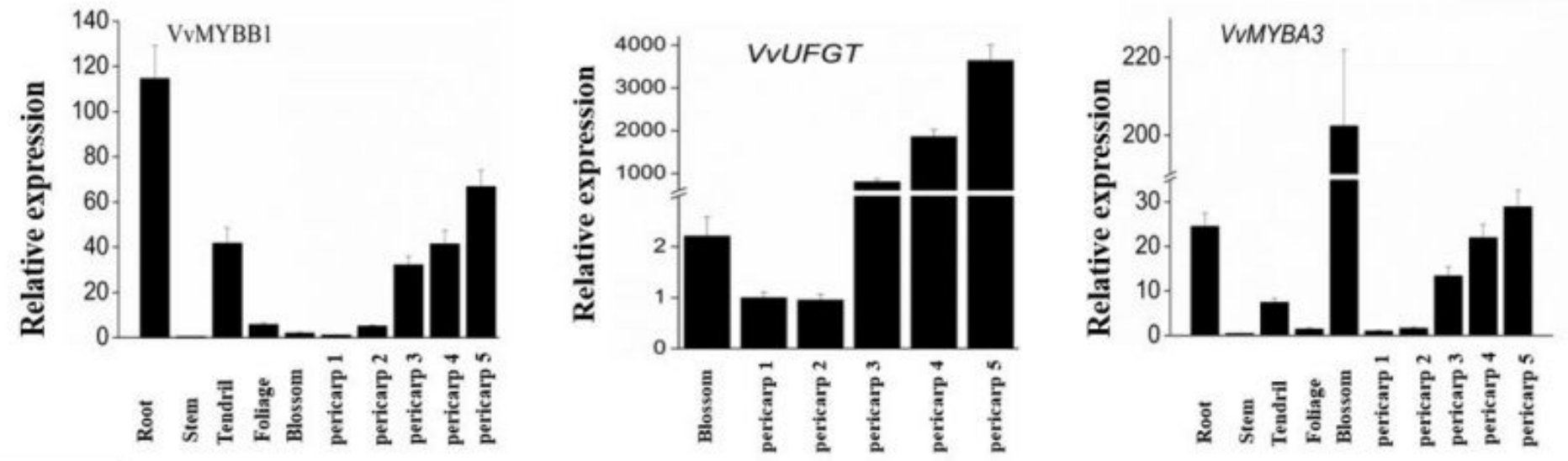

Figure 5

Expression analysis of VvMYB two genes. 

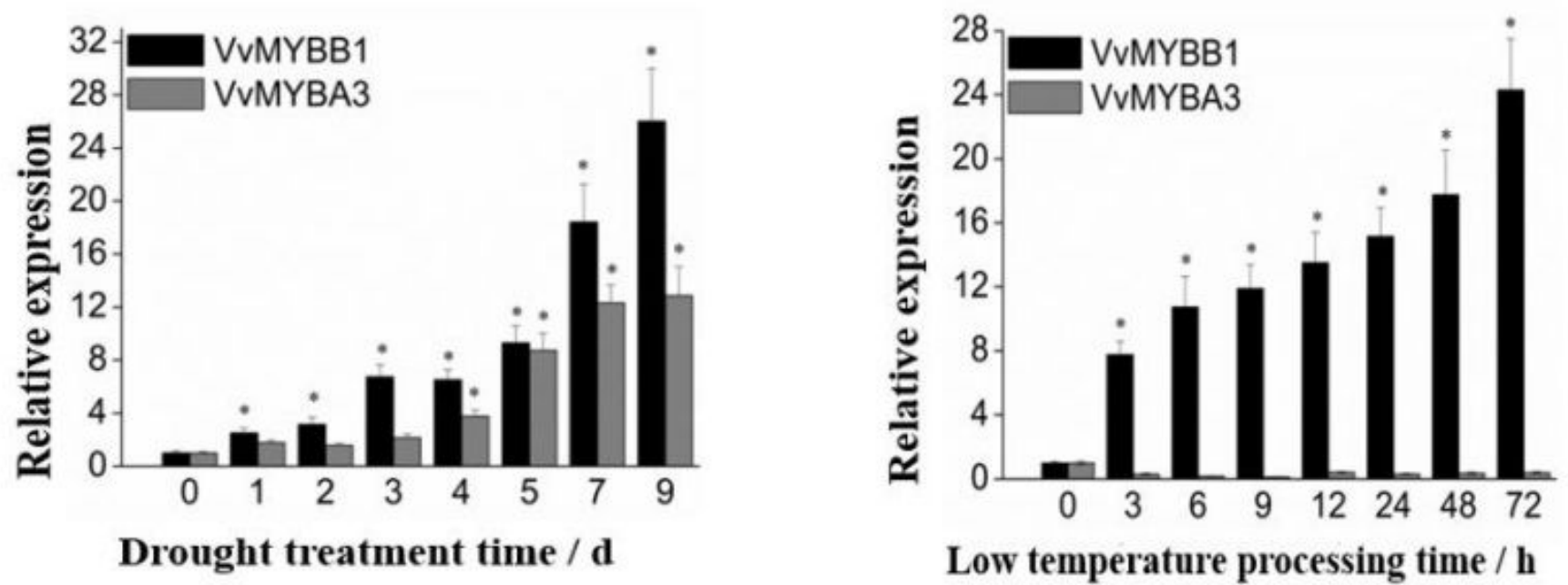

Low temperature processing time / $\mathbf{h}$
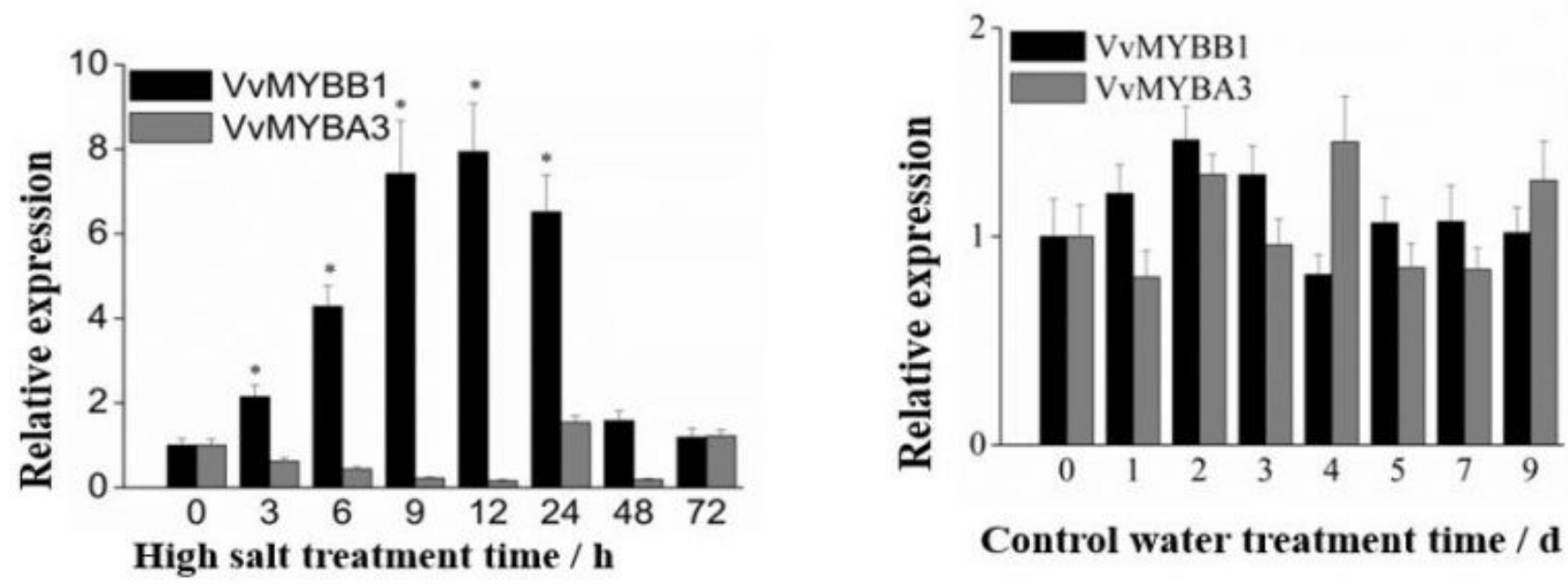

Control water treatment time / d

Figure 6

The relative expression of VvMYBB1 gene and VvMYBA3 gene treated with abiotic stress. 


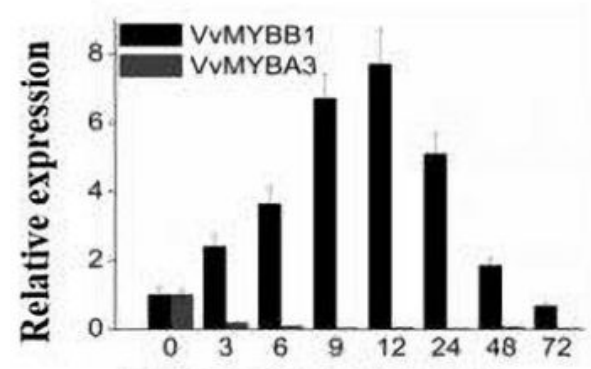

Auxin treatment time / h

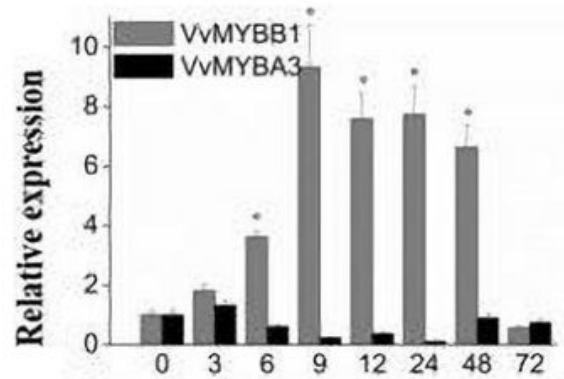

6-benzyl adenine treatment time / h

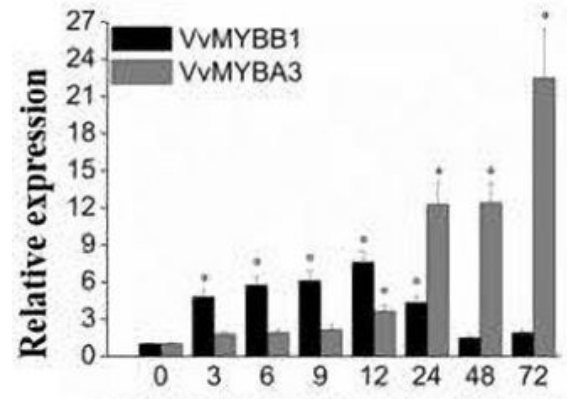

Abscisic acid treatment time / h

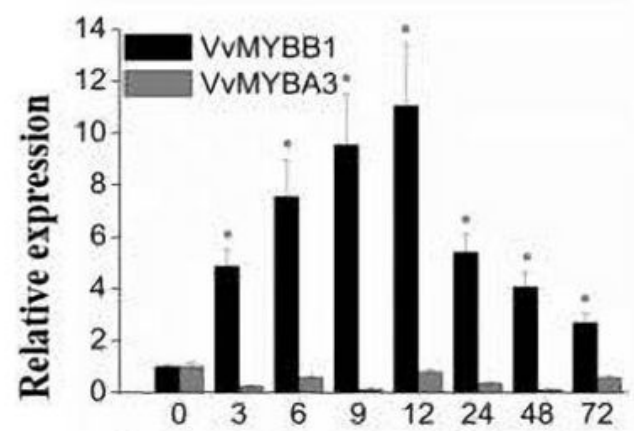

Jasmonate treatment time / h

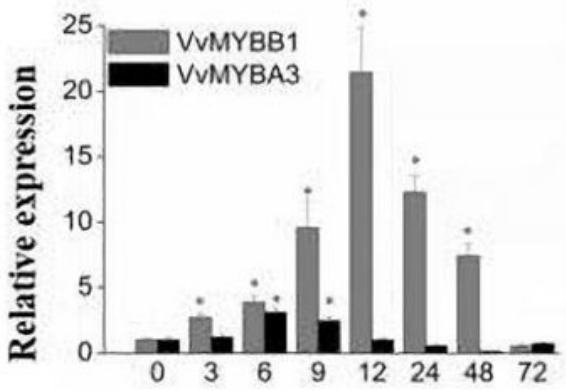

Gibberellin treatment time / h

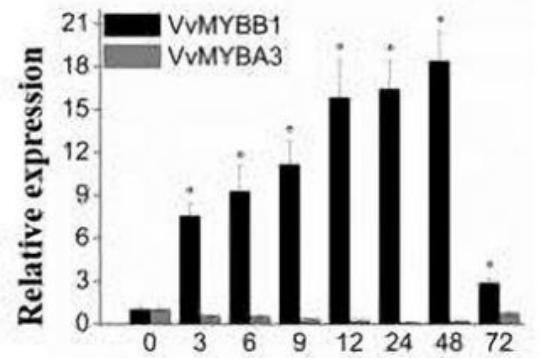

Ethylene treatment time / h

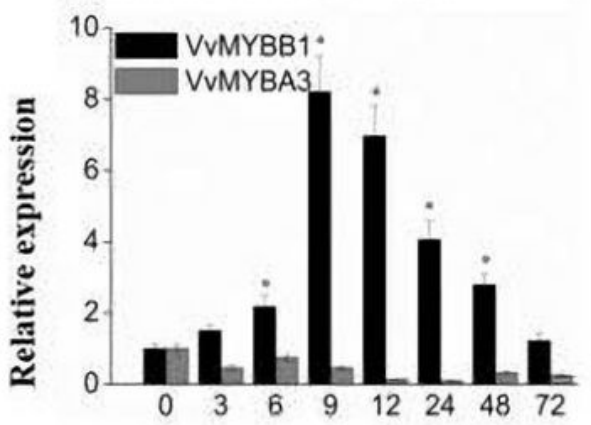

Salicylic acid treatment time / h

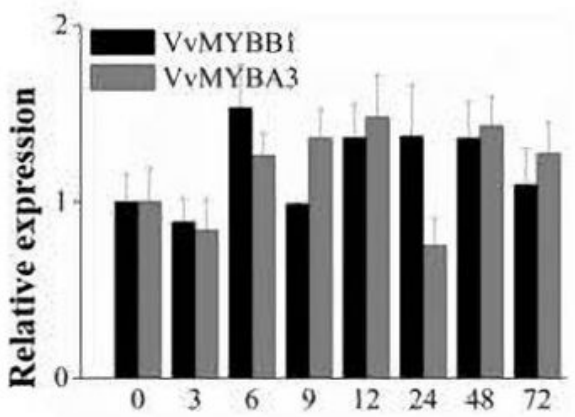

Control water treatment time / h

\section{Figure 7}

The relative expression of VvMYBB1 gene and VvMYBA3 gene treated with hormones. *: Significant differences of genes compared with $0 \mathrm{~h}(\mathrm{P} \otimes 0.05)$. 